\title{
Preface for the Special issue \\ on Design, Concurrent Engineering and Sustainable Manufacturing for Connected Industry
}

It is our great honor to edit this special issue, entitled "Special issue on Design, Concurrent Engineering and Sustainable Manufacturing for Connected Industry" in the Journal of Advanced Mechanical Design, Systems, and Manufacturing. The editorial team of this special issue has selected ten papers mainly, but not limited, from the authors who contributed their work at the International Conference on Design and Concurrent Engineering 2019 \& Manufacturing Systems Conference 2019 (JSME iDECON/MS2019), which was held in Tohoku University, Japan on September 23-24, 2019, organized by Design and Systems Division of Japan Society of Mechanical Engineers, Manufacturing Systems Division in cooperation with Institute of Fluid Science at Tohoku University as well as TMAC.

The conference iDECON was established in Malaysia, Melaka in 2010 as a biannual conference hosted by Malaysia. Now it became an annual conference hosted by both Japan and Malaysia. As stated in the objective of the conference, iDECON is expading under the collaboration between Indonesia-Malaysia-Thailand Growth Triangle (IMT-GT) and Japan. As a result, not only the participants from Japan and Malaysia, but also those from Thailand and Indonesia have submitted/presented high qualified papers with the total number of 43 at the conference in JSME iDECON/MS2019. In addition to these technical papers, two keynotes from Japan/Malaysia, and one workshop were organized so that all of the participants could join and share ideas in each session. The program of JSME iDECON/MS2019 was organized in the following 14 sessions, including Advanced Manufacturing System, Additive Manufacturing, Sustainable Manufacturing Technologies, Lean Manufacturing and Operations Management, Sustainable design and manufacturing, Green technology, Sustainable technology, AI/IoT Application, VR/AR Application, Affective/Kansei design, Educational engineering, Digital-native production, resources and tools, and Data analysis and knowledge visualization.

We would like to express our sincere gratitude not only to the authors who have contributed their papers to this special issue, but also the reviewers who worked very hard to complete their assignment on schedule for publication. We hope that this special issue would encourage further research activities in the field of Design, Concurrent Engineering and Sustainable Manufacturing for Connected Industry.

Chief Editor

Masashi OKUBO (Doshisha University)

Co-Editor

Teruaki ITO (Okayama Prefectural University) 